\title{
Ethical Use of Digital Media and Smartphones: The Quest to restore Human Connectivity
}

\author{
Pragya Lodha ${ }^{1}$, Avinash De Sousa ${ }^{2}$ \\ ${ }^{1}$ Research Assistant, Desousa Foundation, Mumbai. \\ ${ }^{2}$ Founder Trustee, Desousa Foundation and National Trainer, 3T Bioethics Programme. \\ Corresponding Author: Avinash De Sousa \\ Email: avinashdes888@gmail.com
}

\section{The New Media}

There are more than two billion social media users worldwide representing about a global rate of around $28 \%$ of total digital users. In India, the documented number of social media users approximate to 168 million users in 2016. Social networking already accounts for 28 percent of all media time spent online, and users aged between 15 and 19 spend at least 3 hours per day on average using platforms such as Facebook, Twitter and Instagram- across the globe. And 18\% of social media users can't go a few hours without checking different social media platforms before getting up in the morning. This is popularly known as FOMO or Fear Of Missing Out- quite a term for addicted use to social media where one fears to miss out the updates and activities happening on social media platforms [1].

The age of 21st century is that of digital revolution. With its ubiquitous presence, we are surrounded by technology- from personal computers, smart phones, the internet, web and mobile phone applications, to digital assistants, and cloud computing. Digitalization is rampant and new forms of technologies are working their way into every aspect of diurnal practices. Information technology, in retrospect, is technology that records, communicates, synthesizes or organizes information. However, the definition today encompasses wide-ranging tasks [2].

Information can be understood as any useful data, instructions, or meaningful message content. The word literally means to "give form to" or to shape one's thoughts. The digital media or recently known as the new media- are synonymous to the internet and the worldwide web. Online newspapers, websites, podcasts and blogs are examples of new or digital media. The full spectrum of digital space is broad enough that includes technology like the wireless and mobile media, satellite radio, digital television, digital music players, medical interventions, virtual reality, digital cameras and other new or emerging technologies for mediated public communication and health practices. All of this diversity is available for multi-channelled crosscommunication and practice. John V Pavlik defines digital media as "the system of public communication, the systems of content production, distribution and the computer and networkbased technologies that support and shape them" [3].

Pavlik [3] mentions that the transformation of media in the digital age involves at least twelve dimensions. They are -

1. The medium of digital delivery;

2. The devices for accessing, displaying, watching and listening to digitalized media;

3. The audience or users of digital media;

4. The producers of digital media;

5. Digital media content itself;

6. The distributors of media;

7. The financers, owners and business of media;

8. The regulators and law of media;

9. The digital technologies of production (and encryption) that in many ways are fuelling the explosive growth in media production and protection; 
10. The inventors and innovators of next generation media;

11. The ethical framework surrounding or providing context for media;

12. The next generation of media consumers, users and creators - children.

\section{Digital Media: The double-edged sword}

What we experience these years is a pace of technological developments as never seen before. Not only did the World Wide Web and the capacities of digital technologies develop over just a few decades, but the digital revolution expanded into practically every area of life and society over an even shorter period of time. It is estimated that in the year 1986 less than $1 \%$ of the world's media storage capacity was digital and in 2007 it was already 94\% [4]. The year 2002 is assumed to be the year when human kind was able to store more information in digital than in analogue media and is consequently marked as the beginning of digital age.

Information over the media is used for awareness creation, communication, exchange of ideas, exchange of practices, as a learning tool, for medical intervention and therapeutic apparatus; it is an aid for simple daily functions like searching, browsing, knowing, learning and communicating. Among digitalization, social media websites such as Facebook, Instagram, Twitter, and Pinterest as well as the use of smartphones have come to become a significant part of our lives. They are widely used by people across all classes, ages and demography. As with any new technology, they bring both rewards and challenges.

The challenges with digital media include that of ethical usage, its implication on human relationships, link with human behaviour and impact on the overall life of an individual and communities in general. We can consider the following -

1. Netiquettes: A contraction of the word internet and etiquettes, netiquettes are guidelines that govern behaviour when communicating on the Internet. Netiquette covers not only rules of behaviour during discussions but also guidelines that reflect the unique electronic nature of the medium. Poor choices may lead to unpleasant consequences. Netiquette usually is enforced by fellow users who are quick to point out infractions of netiquette rules. A summary of the rules is as follows -

- Identify yourself

- Include a subject line

- Respect others' privacy

- Acknowledge and return messages promptly

- Copy with caution

- No spam (junk mail)

- Be concise

- Use appropriate language

- Use appropriate emoticons to help convey meaning

- Use appropriate intensifiers to help convey meaning

2. Freedom of speech: everyone has the right to freedom of opinion and expression. Freedom of speech is a valid political pathway recognized as a human right under Article 19 of the Universal Declaration of Human Rights. It is a dangerous weapon for specific group of people to manipulate the right to release or spark an unethical sentiment such as racial or religious hatred within the digital space through social media [5].

3. Identity Theft: Identity theft is a form of technique used by criminals to impersonate someone's identity with intention to pursue or commit for crime. The victim is held to be responsible for the consequences of fraud or action done by the impersonators. Identity theft on the Internet can be done either by creating a fake account or stealing and hacking the password of the victim. Awareness about security usage must be inculcated among users [6]. 
4. Leakage of data: Data leakage continues to remain a big issue. It can be traced back where it is most possibly to be caused by user's minimal awareness and understanding on the ethical privacy and protection value on the policies used by each respective social networking sites [7].

5. Cyber bullying: Different from bullying, cyber bullying can take place anytime and anywhere. It is more invasive and carried out largely through social digital means such as social media platforms, e-mails, e-chats and other online platforms of communication. As one of the faster growing trends among the youth, cyber bullying has the potential to target a larger audience. It has a long-standing impact on the affective styles and cognitive patterns of the ones affected, thus, must be prevented in order to secure a sound mental health for the youth [8].

6. Internet privacy: A debatable issue with regard to use of internet is the privacy of an individual in the cyber space. Each and every identity online can be traced and kept record of, therefore, a safety concern with regard to the content and nature of information that goes online is important [9].

7. Digital divide: Digital divide is the lack of access to information and communication technologies among different segments of the society- such as- gender, socio-economic status, race and resource equity. It is when these factors play a role in the division of access to internet and internet services; such as women versus men, poor versus rich, different races and those with inequitable resource availability [10].

8. Digital Affairs: Online affairs of married or committed men and women have created a great deal of divide among relationships. Whether married, unmarried or in a relationship, emotional fidelity is seen on a rise- and this is often also called as social media cheating. Many a times these virtual relationships do take a real form and create a parallel in the real world to the relationships that people have with their spouses. Consequently, relationship issues, divorces, and marriage failures are seen on the rise [11].

9. Cyber footprints: Every online move leaves cyber footprints that are rapidly becoming fodder for research for the people behind screens. Using social media for academic research is accelerating and raising ethical concerns along the way, as vast amounts of information collected by private companies - including Google, Microsoft, Facebook and Twitter are giving new insight into all aspects of everyday life. This can be understood with an example- mining online communication has already helped Microsoft identify women at risk of postpartum depression. It's also allowed Facebook to study how parents and their children interact. The possibilities appear limited only by the imagination of the researchers, which is why such issues come in the spotlight. Increasingly, the human behaviour online is coming under the microscope without people having the knowledge about it [12].

10. Addiction: Addiction to digital (social) media has also been linked to mental health disorders like depression. Studies have also demonstrated the linkage of excessive social media use and reduction in levels of happiness. Other negative impacts of social media include decreased self-esteem, which often goes hand in hand with eating disorders; anxiety; feelings of insecurity and deterioration in concentration and other symptoms of ADHD [13].

\section{Should Digital Media Use Be Supervised}

Apart from understanding the above stated issues that are prevalent with the rise in internet use, pervasive technological use in our lives has hugely impacted the space of our interpersonal 
relationship. It has become an ever-increasing problem with a breadth of technologies available to make internet just a click away- from smartphones to tablets to ipads and computer, laptops and palmtops. Additionally, despite the formulated rules in practice, we see underaged children using social media- the age for use of internet is also decreasing. Cyber-crimes are alarmingly high and behavioural addictions like the internet addiction, online shopping addiction, online pornography addiction and video game addiction are being reported. The complexities of technological luxury have invaded the privacy and essence of human relationships [13].

\section{CONCLUSIONS}

Therefore, it is necessary that we imbibe certain guidelines while using the digital media -

1. You can reach out, offline: by substituting your social media time with interpersonal activities with family members and friends, you can cut back and limit the hours you spend online. Replenish the non-virtual relationships that you can depend and trust on. Research claims that detaching and disconnecting from real relationships can be as harmful as smoking 15 cigarettes.

2. You could put down your phone and other devices when with friends on an outing. Investing in relationships that are around you is important for your well-being.

3. Physically tune up your mind and body: Spend time to exercise and meditatethat can strengthen your muscles and boost a positive mood.

4. Don't compromise sleep. Sleep is of great importance to promote a healthy lifestyle and good mental health.

5. Unplug and erase: take social media off your radar by uninstalling apps, removing shortcuts from your home screen and bookmarks from your browser. This makes getting to social media more effortful and a longer process.

6. Spread an awareness among children, youth and everyone about the responsible use of social media and internet.

7. Monitor social media and internet use for children below the age of 16 years to ensure safety and security. Parents can monitor use by deterring access to certain websites deemed unfit for the age of the child. A track can also be kept about he social media friends of their child.

8. Keep family hours of 'no social media use' to inculcate the culture in your children and spend quality time with family. Everyone in the family must follow this. Dinner time of the day can also be kept free from using any gadgets. A family that eats together, stays together.

9. Schools can actively participate in advocating for safer use of internet and making students aware of the ill-effects of digital media.

10. You can also set firm boundaries by restricting your social media time and get support either from friends and families or local and national organisations specialising in mental health and measures to keep social media addiction at distance.

\section{REFERENCES AND RECOMMENDED READING}

1. Thomas PN. Digital India: understanding information, communication and social change. SAGE Publications India; 2012.

2. Bomsel O, Ruet J, Cognet S, Durpthy T, El Khoury A, Maria A, Masclet P, Vannier B. Digital India: Report on the Indian IT industry. CERNA. 2001.

3. Pavlik JV. Video games beat Hollywood. Television Quarterly 2008;38(3):3-13.

4. Coleman EG. Ethnographic approaches to digital media. Ann Rev Anthropol 2010;39:487-505.

5. Barendt E. Freedom of speech. Oxford University Press; 2005.

6. Krasnova H, Günther O, Spiekermann S, Koroleva K. Privacy concerns and identity in online social networks. Identity in the Information Society 2009;2(1):39-63.

7. Gantz J, Reinsel D. The digital universe in 2020: Big data, bigger digital shadows, and biggest growth in the far east. IDC iView: IDC Analyze the future 2012;2007(2012):1-6.

8. Slonje R, Smith PK. Cyberbullying: Another main type of bullying?. Scand J Psychol 2008;49(2):147-54. 
9. Dinev T, Bellotto M, Hart P, Russo V, Serra I. Internet users' privacy concerns and beliefs about government surveillance: An exploratory study of differences between Italy and the United States. J Glob Inform Manage (JGIM) 2006;14(4):57-93.

10. Norris P. Digital divide: Civic engagement, information poverty, and the Internet worldwide. Cambridge University Press; 2001.

11. Merkle ER, Richardson RA. Digital dating and virtual relating: Conceptualizing computer mediated romantic relationships. Fam Relat 2000;49(2):187-92.

12. Golder SA, Macy MW. Digital footprints: Opportunities and challenges for online social research. Ann Rev Sociol 2014;40:129-54.

13. De Sousa A. Parenting in a Digital Era. St Pauls Better Yourself Books ; 2017.

Acknowledgements - Nil

Source of Funding - Nil

Conflict of Interest $-\mathrm{Nil}$ 